\title{
Electric and biomethane-fuelled urban buses: comparison of environmental performance of different powertrains
}

\author{
Giampiero Mastinu $^{1}$ (D) $\cdot$ Laura Solari $^{1}$
}

Received: 27 February 2021 / Accepted: 22 November 2021 / Published online: 12 January 2022

(c) The Author(s) 2022

\begin{abstract}
Purpose The paper aims to promote the transition to low/zero emission of the local public transport, particularly, urban buses are taken into account.

Method The life cycle assessment of electric and biomethane-fuelled urban buses is performed by exploiting SimaPro commercial software (v.9.1.1.). Attention is focused on powertrains. Both midpoint and endpoint analyses are performed. Referring to environmental impact, the best compressed biomethane gas (CBG) powertrain was compared to the best electric one. Additionally, the worst-case scenario has been considered for both CBG and electric powertrains.

Results CBG powertrain outperforms the electric one if overall greenhouse gas emissions are considered. However, the electric powertrain seems promising for human health and ecosystem.

Conclusions The environmental performance of the two powertrains is good. Both of the two technologies have strength and weak points that anyhow make them good candidates for a clean local public transport of the future. The analysis performed in the paper suggests a future investigation on hybrid electric-CBG powertrain. Actually, such a solution could benefit from both the strengths of the biomethane and the electric powertrain.
\end{abstract}

Keywords Urban buses $\cdot$ Biomethane $\cdot$ Environmental performance

\section{Introduction}

Many of the 17 Sustainable Development Goals of the United Nations (2020) foster - directly or indirectly - a cleaner transport system. Precisely, Goal 13 "Take urgent action to combat climate change and its impacts" is fully relevant for the research presented in this paper. Other relevant goals are Goal 7 (energy for all), Goal 9 (sustainable industrialization and innovation), Goal 10 (make cities sustainable), Goal 12 (sustainable consumption), Goal 14 (sustainable oceans and seas), and Goal 15 (protect terrestrial ecosystems).

The European Union and its Member States in recent years have also pledged to reduce the greenhouse gas (GHG)

Communicated by Xin Sun.

Giampiero Mastinu

gianpiero.mastinu@polimi.it

1 Department of Mechanical Engineering, Politecnico di Milano, Via privata Giuseppe La Masa, 1, 20156 Milan, Italy levels with the Paris Agreement (UNFCCC 2016) and the Green New Deal (European Commission 2019). These initiatives have urged the creations and further development of policies that directly target urban buses for a cleaner and more sustainable sector. The European Commission (2020) has clearly stated an agenda to reduce to zero the emission of the transport sector by 2050. Actually, the second goal of the Agenda states: "By 2050, nearly all cars, vans, buses as well as new heavy-duty vehicles will be zero-emission." Another similar agenda was published in the USA by EPA (2016) which stated a substantial reduction of greenhouse gas emissions from commercial trucks and buses by 2027 .

The local public transport sector will acquire in the future a greater importance (Spielmann et al. 2005). Actually, according to PWC (2016), one of the mega-trends of the global economy is "accelerating urbanization." Due to urbanization, an increase of urban traffic is expected; this will have a dramatic effect; in fact, nearly $80 \%$ of the surface traffic in the world occurs within cities.

According to Ciuffo and Raposo (2020), we are witnessing a revolution of local transport, where the main drivers are represented by low-carbon technologies and 
connectivity, automation, and shared mobility. This technological development will lead to a higher sustainability of transport (Papadimitriou and Mellios 2020). Public transport is a non-negligible factor when it comes to lowering the impact of greenhouse gases (GHG) and particulate matter (PM) especially in urban areas (Ciuffo and Raposo 2020).

To assess the overall environmental impact of an urban bus, it is not enough performing a well-to-wheel (WTW) analysis of the emissions due to operating conditions. The impact on the environment is to be fulfilled by performing a life cycle analysis (LCA) that takes into account all emissions through a cradle-to-grave approach. The problem of LCA is that it is reputed more difficult to be acknowledged than WTW (Joint Research Centre 2020). JEC (collaboration between JRC-Eucar -Concawe) periodically publishes a well-to-wheel report on the greenhouse gas (GHG) emissions, energy use, and powertrain configurations in Europe (Prussi et al. 2020), comparing actual consumption and emission scenarios with future projections relative to 2030 (Joint Research Centre 2020). The focus on WTW emissions is mainly on the $\mathrm{CO}_{2}$, as discussed by Johnson (2010).

LCA has been applied to compare different automotive technologies since many decades ago. A recent query of the SAE Mobilus database has provided 633 entries related to the application of LCA to automotive technology. For sake of space, the results of the query are not reported in this paper. A remarkable result of the query is that no papers were written on the LCA of buses fuelled with biomethane.

An additional query focused on the Journal of LCA provided a number of papers on the comparison of different types of buses (Bouter et al. 2020; Velandia Vargas et al. 2019; Duan et al. 2017; Ercan and Tatari 2015; Choi and Song 2014). Again, no reference was made to buses fuelled with biomethane.

To cover the experienced gap, this paper focuses on the comparison between compressed biomethane (CBG)-fuelled urban buses and electric ones. The comparison seems quite reasonable in view of a reduction of emissions in the local public transport. Attention is devoted to powertrains only.

The use of alternative fuels such as biofuels in urban public transport seems extremely relevant. The role of biomethane in the transport sector, from road to naval applications, has been widely studied as discussed by various organizations like the EU (Grigoratos et al. 2015), UITP (2020a, b) and companies like Ricardo (Kollamthodi et al. 2016). As for biomethane urban buses, the benefits of using compressed biomethane gas (CBG) in cities has been investigated and compared to the use of fossil methane (Fearghal and Caulfield 2010). The research focused mainly on the analysis of the renewable methane production and on the optimal production configuration.

The production of biomethane is still a technology under development. A complete LCA for the anaerobic digestion shows the impact, possibilities, and limits of this technology (Timonen et al. 2019). The biogas deployment emissions are analysed in a 2-part comprehensive review that shows how differently particulates and $\mathrm{CO}_{2}$ emissions vary depending on different parameters such as digestion scenarios, biogas utilization, and waste stream scenarios (Poeschl et al. 2011, 2012). In this framework, also, the chosen methodological approach, attributional or consequential, affects the results of the analysis depending on the allocation of products and subsystems for biomethane energy production (Rehl et al. 2012).

As for heavy duty vehicles in the class M3 for public transport, different research papers have been analysed. None of the following papers considered CBG buses.

Nordelöfa et al. (2019) studied the LCA of city buses powered by electric motor or diesel engine. As expected, the results are deeply affected by the electricity production process. Another comparative LCA of electric and diesel city buses was performed by Mendoza et al. (2018). Different future scenarios were examined. Different emission mitigation scenarios were considered, with the development of emerging technologies as possible variables. Concerns on the long term influence on LCA results were addressed by Mendoza et al. (2018), Beltran et al. (2020). Bouter et al. (2020) addressed the environmental tradeoffs in road passenger transportation between conventional buses and electrified buses using LCA methodology. Velandia Vargas et al. (2019) evaluated what would be the environmental impact of manufacturing BEVs and battery electric buses (BEBs) in Brazilian southeast. A conventional bus was used for comparison with electric buses. Cox et al. (2017) analysed by LCA different powertrain technologies of urban buses; unfortunately, the biomethane-fuelled buses were not considered. Duan et al. (2017) analysed the carbon footprint in the public transport sector in the Shenzen area. Despite a lot of efforts to promote electric buses in Shenzhen, their effectiveness seems rather limited. Referring to the New York area, Ercan and Tatari (2015) presented total air pollutant emissions and water withdrawal impacts through the lifetime of a transit bus with different fuel options. Choi and Song (2014) analysed CNG bus emission in Korea.

An example of a site-dependent LCA for urban transportation was discussed in a study by the Energy and Resources Institute of New Delhi, where the Metro rail and the Bus and Rapid Transit Systems (BRTS) were compared (Ghate and Qamar 2020). In the LCA literature, the end-of-life framework for city buses is also investigated as described in the review by Schwarz et al. (2019) to avoid resource short-falls of the needed resources in the production of alternative propulsion systems. Finally, Russell (2019) states correctly that for a comparative LCA, the evaluation of emissions must be carefully performed through the most appropriate method. 
For electric vehicles, many LCA studies show their environmental performance. In the case of plug-in vehicles, many studies have been performed for light vehicles, comparing their environmental profile with a standard internal combustion engine (ICE) vehicle (Silvestri et al. 2019).

Just a paper was found dealing with CBG buses. Shanmugam et al. (2019) assessed the benefit of introducing biomethanefuelled buses in Mumbai, with successful effects. An indepth comparison between different types of powertrains was missing.

All the mentioned LCAs tackle very complex products, such complexity must be carefully interpreted and analysed. In the paper, a special care will be devoted to complexity, but the focus will be on product and process only. Mathe (2014) and Spielmann et al. (2005) focused the attention on social life cycle assessment (SLCA), in particular in the transport sector. We do believe that SLCA is relevant but out of the scope of this paper.

The LCI on which the paper is based is reported in the public repository of the Politecnico di Milano (See the "Data" section).

Considering the GHG emissions, the best CBG powertrain will be compared with the best electric powertrain. This seems a rigorous way to compare two different complex systems (Mastinu et al. 2006). A brief justification of the comparison method is given in the paper.

The paper is structured into three main parts.

Firstly, all the hypothesis and assumptions of the study are listed for comparing electric and biomethane-fuelled urban buses.

As a second step, in the inventory analysis, the bill of materials (BOM) for the two powertrains under comparison are defined. All the components are briefly described with their use application in the powertrain. All data for fuel production, emissions, and maintenance are categorized into the possible scenarios. These values are the input value for the LCA.

Then at the LCIA level, the ReCiPe interpretation method for the results is introduced, and results are displayed and discussed. An additional sensitivity analysis to check the effect of maintenance on the vehicle is performed.

Finally, in the conclusion, all results are summarized with possible future developments of the study.

\section{Goal and scope definition}

According to the EN ISO 140402006 LCA procedure, the goal and scope definition are hereafter given.

The functional unit of the study is a 12-m-long urban bus, with a service life of 14 years. The daily travelled distance is $150 \mathrm{~km} ; 53$ days are the working days per year; $630,000 \mathrm{~km}$ is the travelled distance of the whole bus life. The data make reference to the average life of an urban bus in Italy. Both buses are considered to be operating at maximum passenger capacity. The data from Italy about operating life of the vehicle is in line with European traffic data (UITP 2019).

In Fig. 1, the cradle-to-gate and cradle-to-grave life spans are depicted.

The paper adopts the following hypotheses.

- Only the powertrain is considered. All of other parts of the urban bus are not considered in the LCA. Actually, the electric and biomethane-fuelled urban bus bodies are composed by (nearly) the same parts.

- No assembly and transport of components is considered; in other words, the environmental impact due to the production of components in different sites of the world is neglected.

- No LCA analysis is performed referring to fuelling infrastructure; i.e., the environmental impact related to

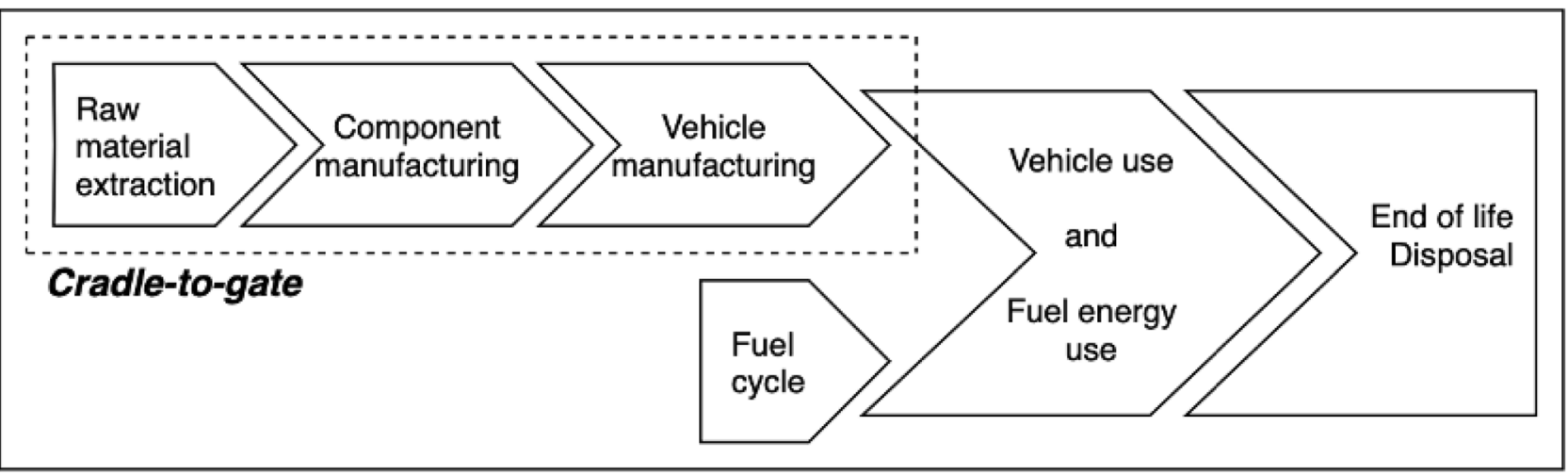

Cradle-to-grave

Fig. 1 Cradle-to-gate and cradle-to-grave for a road vehicle such as an urban bus 
the manufacturing, usage, and maintenance of charging stations for electric vehicles is neglected. The same approach has been followed for fuel stations of conventional buses.

- The end of life for both buses is bare disposal. This is a worst-case scenario.

\section{Inventory analysis (LCI)}

In the following sections, the cradle-to-grave analysis of the product is approached by initially dividing it into a cradleto-gate part, considering the finished vehicles after their production (electric and CNG cases), the use of the vehicle, by taking into account the needed fuel for transit, and the maintenance of the product.

\subsection{Bill of materials}

All the datasets were integrated with Ecoinvent 3.6 dataset. The inventory analysis is based on the bill of materials of the two different powertrains under comparison.

Figure 2 shows a sample of the BOM for the internal combustion engine (ICE) bus. The BOMs have been generated from real and literature information of components/processes. (STARK Automotive 2020), (ZF 2019), (MercedesBenz 2019), (Iveco Bus 2020a, b), (Faber cylinders 2020).
Table 1 Percentages of waste material for production processes

\begin{tabular}{lll}
\hline Process & Output (\%) & $\begin{array}{l}\text { Scrape } \\
\text { material } \\
(\%)\end{array}$ \\
\hline Turning (axles) & 95 & 5 \\
Turning (gears) & 80 & 20 \\
Milling & 98 & 2 \\
Surface finishing (grinding) & 100 & 0 \\
Drilling & 98 & 2 \\
Sheet metal cutting & 60 & 40 \\
Die casting & 98 & 2 \\
Injection moulding & 100 & 0 \\
Forging & 100 & 0 \\
\hline
\end{tabular}

The data for the parts' quantity and mass is taken from literature and from known design of the urban buses (STARK Automotive 2020). It was not possible to obtain foreground data for all production processes of the parts, and thus, the transformations and machining of the components were hypothesized as in Table 1 . The definition of the bill of materials (BOM) for the two powertrains is close to the real case, the most relevant components were considered, together with minor components, such as screws, seals, washers, and nuts.

The powertrain of the CBG vehicle is made up of six main systems: ICE engine, engine cooling system, transmission,

\begin{tabular}{|c|c|c|c|c|}
\hline System & Components & Subcomponents & Quantity & Material and processes (ecoinvent data) \\
\hline \multirow{14}{*}{$\begin{array}{l}\text { Three-phase } \\
\text { asynchronous electric } \\
\text { motor }\end{array}$} & \multirow[t]{9}{*}{ Stator } & \multirow[t]{2}{*}{ Outer case } & $4 \mathrm{~kg}$ & \begin{tabular}{l|l|l|l} 
Aluminium, primary, ingot $\{\mathrm{GLO}\}$ & production & Cut-off, S \\
\end{tabular} \\
\hline & & & $4 \mathrm{~kg}$ & $\begin{array}{l}\text { Casting, aluminium, lost-wax }\{\mathrm{GLO}\} \mid \text { casting, aluminium, lost- } \\
\text { wax | Cut-off, S }\end{array}$ \\
\hline & & \multirow{3}{*}{$\begin{array}{l}\text { Windings and } \\
\text { coils }\end{array}$} & $55 \mathrm{~kg}$ & Copper $\{$ GLO\}| production, primary | Cut-off, S \\
\hline & & & $55 \mathrm{~kg}$ & Wire drawing, copper $\{$ GLO $\} \mid$ processing $\mid$ Cut-off, S \\
\hline & & & $55 \mathrm{~kg}$ & $\begin{array}{l}\text { Metal working, average for copper product manufacturing } \\
\{\text { GLO\}| processing | Cut-off, S }\end{array}$ \\
\hline & & \multirow[t]{2}{*}{$\begin{array}{l}\text { Structure } \\
\text { laminae }\end{array}$} & $37.31 \mathrm{~kg}$ & $\begin{array}{l}\text { Silicon, multi-si, casted }\{\text { GLO }\} \mid \text { market for silicon, multi-Si, } \\
\text { casted | Cut-off, S }\end{array}$ \\
\hline & & & $37.31 \mathrm{~kg}$ & Silicon, multi-Si, casted \{GLO\}| production | Cut-off, S \\
\hline & & Resin structure & $0.97 \mathrm{~kg}$ & Polyester resin, unsaturated $\{\mathrm{GLO}\} \mid$ production | Cut-off, $\mathrm{S}$ \\
\hline & & Resin slots & $4.2 \mathrm{~kg}$ & Polyester resin, unsaturated $\{\mathrm{GLO}\} \mid$ production | Cut-off, $\mathrm{S}$ \\
\hline & \multirow[t]{5}{*}{ Rotor } & \multirow[t]{2}{*}{$\begin{array}{l}\text { Structure } \\
\text { laminae }\end{array}$} & $41.08 \mathrm{~kg}$ & $\begin{array}{l}\text { Silicon, multi-si, casted }\{\mathrm{GLO}\} \mid \text { market for silicon, multi-Si, } \\
\text { casted | Cut-off, S }\end{array}$ \\
\hline & & & $41.08 \mathrm{~kg}$ & Silicon, multi-Si, casted \{GLO\}| production | Cut-off, S \\
\hline & & Resin structure & $7.1 \mathrm{~kg}$ & Polyester resin, unsaturated \{GLO\}| production | Cut-off, S \\
\hline & & Bearings & $0.32 \mathrm{~kg}$ & 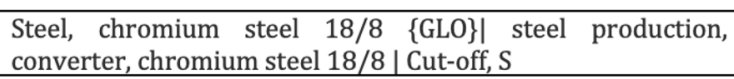 \\
\hline & & Bearings & $0.14 \mathrm{~kg}$ & $\begin{array}{l}\text { Chromium steel removed by milling, dressing }\{\text { GLO }\} \mid \\
\text { chromium steel milling, dressing } \mid \text { Cut-off, S }\end{array}$ \\
\hline
\end{tabular}

Fig. 2 Part of the inventory analysis of the electric motor of the urban bus under consideration. The full inventory data can be retrieved from the public repository of the Politecnico di Milano, see the "Data" section at the end of the paper 


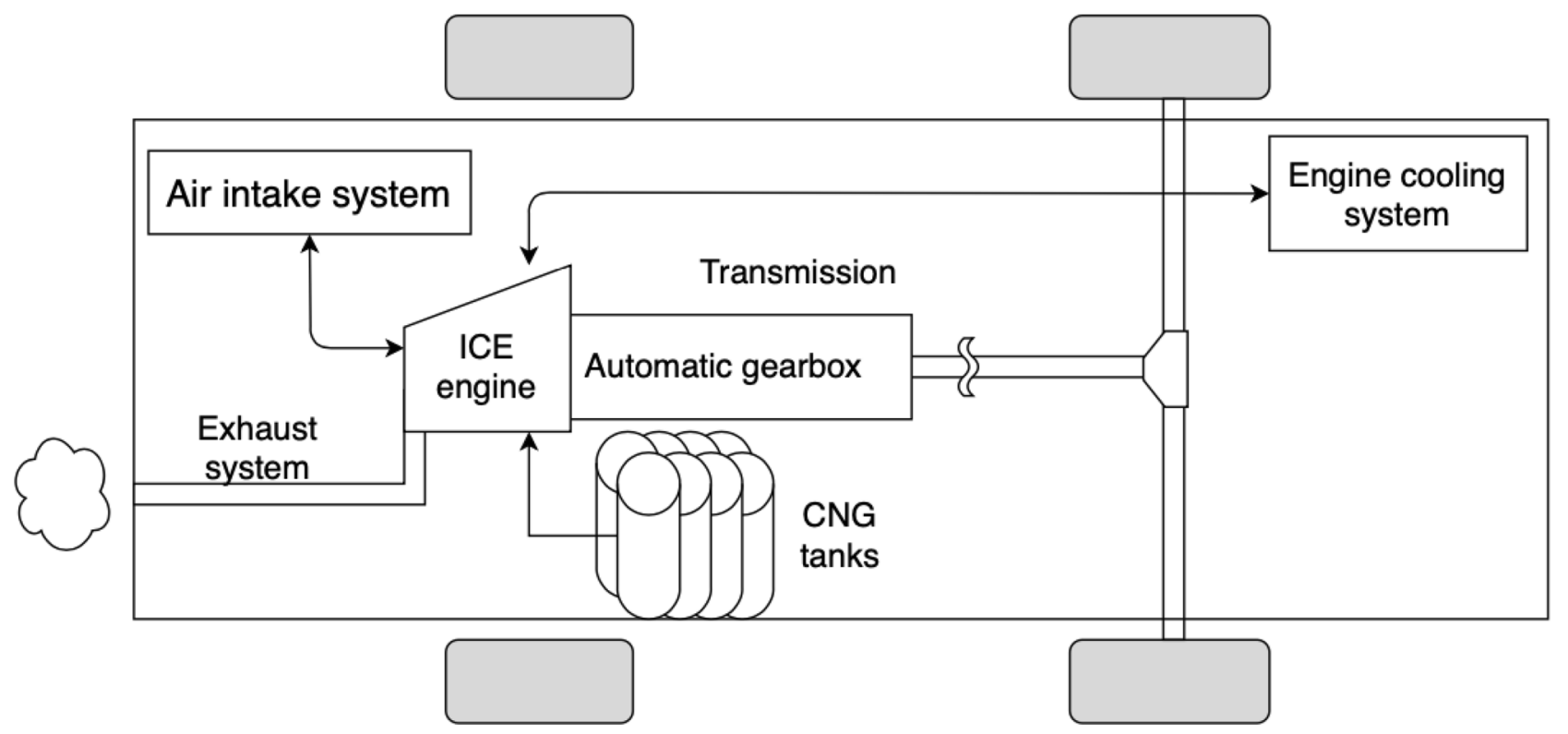

Fig. 3 Powertrain of the CBG urban bus

air intake system, CNG tanks, and exhaust system. The most complex system is for sure the ICE engine that has a number of subsystems identifiable with engine block, head, injection system, starter electric motor, permanent magnet alternator. Overall, the CBG powertrain has 319 parts for the 89 different components (screws and similar minor pieces are considered all together in homogenous sets).
The electric powertrain is composed by a smaller number of components ( 44 different parts for about 150 total components), that are divided into three-phase asynchronous motor and inverter (ZF 2020), battery pack (Argonne National Laboratory 2012), engine and battery cooling systems, transmission, and wiring (again, screws and similar parts are considered all together). We have not included an

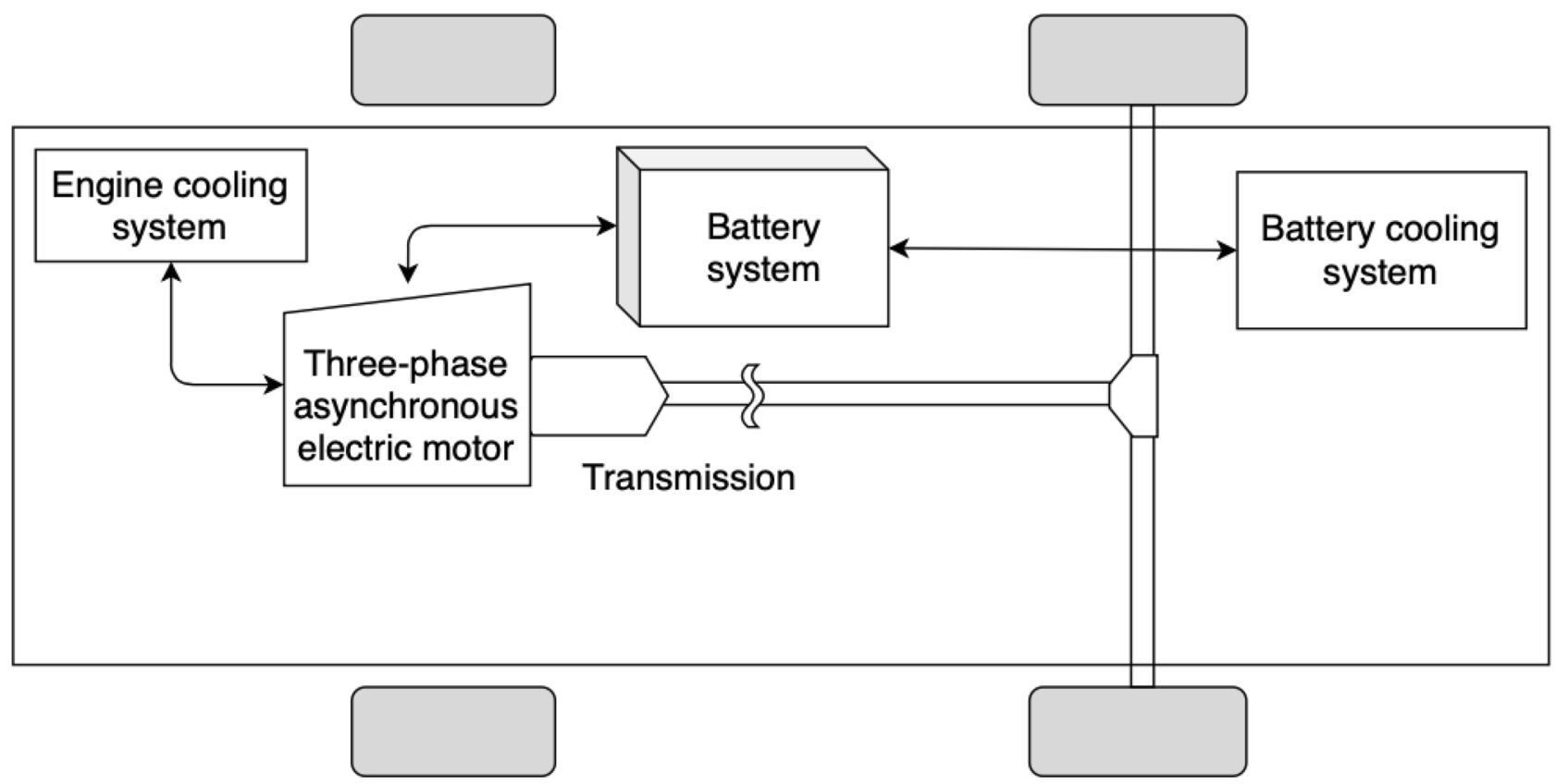

Fig. 4 Powertrain of the electric urban bus 
Table 2 Avoided emissions from the upcycling of manure into biomethane

\begin{tabular}{llll}
\hline Product & $\begin{array}{l}\text { Emissions in kton for 181 million } \\
\text { tons of manure }\end{array}$ & $\begin{array}{l}\text { Emissions in kg for 1 ton of } \\
\text { manure }\end{array}$ & $\begin{array}{l}\text { Emissions in } \mathbf{g} \text { for } \\
\mathrm{kg} \text { 1 of biomethane }\end{array}$ \\
\hline NH3 & 326.5 & 1.8038 & 49.3 \\
VOC & 291.1 & 1.6082 & 43.9 \\
TPM & 338.2 & 1.8685 & 52.1 \\
PM10 & 215.5 & 1.1906 & 32.5 \\
PM2.5 & 32 & 0.1768 & 4.83 \\
\hline
\end{tabular}

on-board battery charger because we did want to consider the best electric vehicle in terms of LCA impact. This is achieved by limiting the number of components.

A schematization of the two powertrains can be found in Figs. 3 and 4.

Figure 3 shows the powertrain of the CBG urban bus. Figure 4 shows the powertrain of the electric urban bus.

\subsection{Bus mission}

The needed energy for the mission of the two buses (wellto-wheel) is evaluated as shown below.

The chosen scenario considers a fully renewable mix both for electricity and biomethane production from manure.

Considering a methane consumption of $0.53 \mathrm{~kg} / \mathrm{km}$ (Mastinu et al. 2020; CLM 2021), the overall use of methane during the life cycle $(630,000 \mathrm{~km})$ of the CBG urban bus totals to 333.9 tonnes of methane. It is estimated that Italy has a potential production of 8 billion $\mathrm{Nm}^{3}$ of biomethane from all feedstocks (CIB et al. 2016). This of course shows the potential of biogas and biomethane production in Italy. This is also true for Europe, where IEA study for Bioenergy Task (IEA 2020) shows how Sweden and Germany take the lead worldwide for commercial biogas upgrading plants with respectively 55 and 96 plants (Giuntoli et al. 2017). In the framework of circular economy, this potential could be fully exploited. Therefore, for the assessment, the feedstock chosen for biomethane production lands on cattle and pig manure. The production of biomethane also accounts for avoided emissions in the environment that are shown in Table 2 (National Collaborating Centre for Environmental Health 2011; Agostini 2006).

The production of biomethane from manure shows an allocation problem relative to the production of the fertilizer from the residual digestate. Fertilizer production was included to avoid the allocation problem; this was possible by using the consequential approach. This coproduct is considered within in the boundaries of this LCA study as represented in Fig. 5. The data for fertilizer production is given in the "Data" section. For the biomethane extraction, the work by Duan et al. (2020). was taken as reference.

For the estimation of the needed electricity for the mission of the bus, an average value of $1.25 \mathrm{kWh} / \mathrm{km}$ was considered (Mastinu et al. 2020; CLM 2021). Thus, a grand total of 787,500 kWh per bus is needed in its entire life cycle.

The choice on renewable energy landed on low voltage electricity production. Field solar panels were considered. Plants with a total capacity of $570 \mathrm{kWp}$ in an open ground installation were taken into account. The slanted roofs were not considered as a feasible solution for the production of photovoltaic energy.

Note that both data for fuel consumption (electric and CBG) are in line with SORT data (UITP, and a study on real data consumption values by Gis et al. (2017).
Fig. 5 Flow chart of the biomethane production (anaerobic digestion)

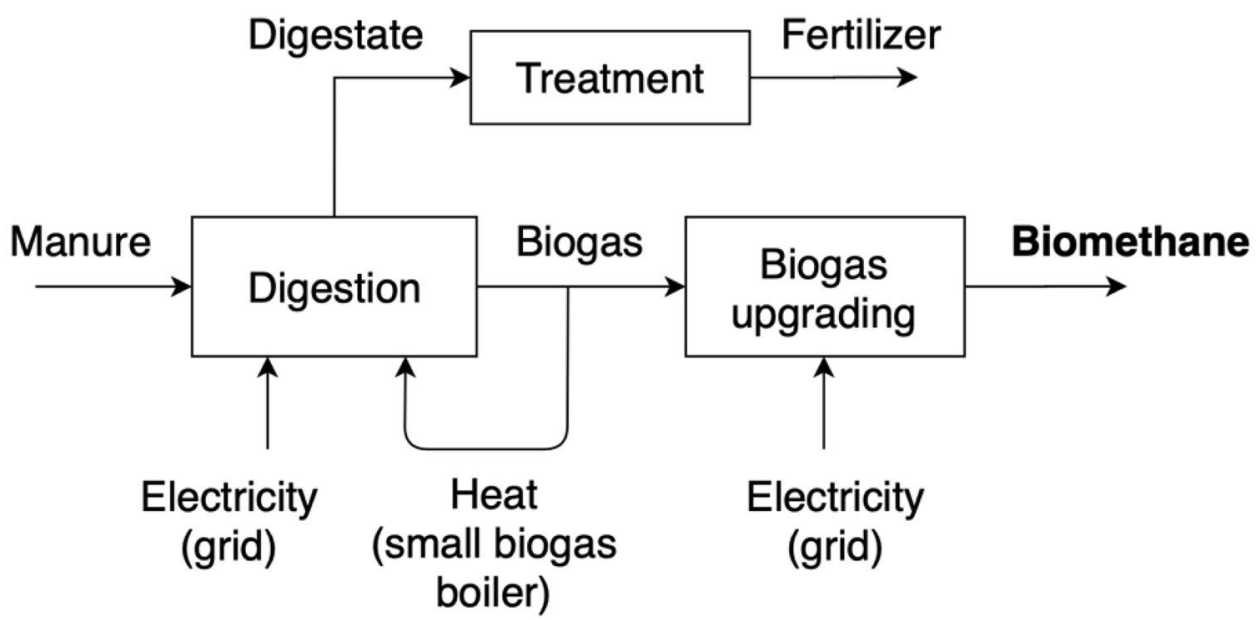


For the CBG vehicle, local combustion is considered in the tank-to-wheel emissions. The data set presented by ISPRA in 2018, related to emissions of a CBG bus in an urban environment, is considered. These data represent the average emissions of the category of enhanced environmentally friendly vehicles (EEV). In order to make these data compliant to the Euro VI standards, the emission values that are regulated by the standard are set to the maximum value allowed, while all other pollutants are left unchanged. Four sets of data are considered for the combustion of the biomethane to verify possible errors and variabilities of records; this is discussed in the consistency check of the data.

As for maintenance, the electric bus requires two additional battery packs in order to have a constant efficiency in its use, totalling to three in its life cycle. The CBG bus on the other hand has the battery for the auxiliaries replaced. This is in compliance with today's technology for powertrain batteries since the average life for a battery pack for an electric vehicle is around 200 thousand kilometres. Considering the $630,000 \mathrm{~km}$ estimated, two additional battery packs during maintenance were added, totalling to three battery packs for the electric bus life cycle (Zhang et al. 2021; Dai et al. 2019) (Tables 3 and 4).

Table 5 depicts the described scenarios related to powertrain energy supply, emissions, and maintenance of the two different types of buses.

\section{Impact assessment (LCIA)}

The method used for the evaluation of the output given by the Inventory Analysis is the ReCiPe method (PRé Sustainability 2016; PRé Consultant 2020; PRé Various authors

Table 3 Emissions for an EEV urban bus in air (Copert, Emisia 2020)

\begin{tabular}{ll}
\hline Substance & $\begin{array}{l}\text { Emissions } \\
\text { in air }(\mathrm{g} / \\
\mathrm{km})\end{array}$ \\
\hline Carbon monoxide $(\mathrm{CO})$ & 0.944 \\
Volatile organic compounds (VOC) & 0.9634 \\
Non-methane volatile organic compounds (NMVOC) & 0.0166 \\
Nitrogen dioxide $\left(\mathrm{NO}_{2}\right)$ & 0.1573 \\
Particulates $2.5 \mu \mathrm{m}(\mathrm{PM} 2.5)$ & 0.0658 \\
Particulates $10 \mu \mathrm{m}(\mathrm{PM} 10)$ & 0.1212 \\
Methane & 0.98 \\
Carbon dioxide $\left(\mathrm{CO}_{2}\right)$ & 1105 \\
Lead & 0.1318 \\
Cadmium & 0.0037 \\
Copper & 1.6347 \\
Chromium & 0.063 \\
Nickel & 0.0296 \\
Selenium & 0.0039 \\
Zinc & 0.5964 \\
\hline
\end{tabular}

Table 4 Emissions for an EEV urban bus in soil (Copert)

\begin{tabular}{lc}
\hline Susbtance & $\begin{array}{c}\text { Emissions in } \\
\text { soil }(\mathrm{mg} / \mathrm{km})\end{array}$ \\
\hline Cadmium & 0.0005 \\
Lead & 131.8 \\
Copper & 1.0924 \\
Chromiun & 0.0496 \\
Nickel & 0.0074 \\
Selenium & 0.0007 \\
Zinc & 0.2826 \\
\hline
\end{tabular}

2020). In the assessment, both 18 midpoint impact factors and 3 endpoint factors, damage oriented, are considered. The midpoint impact factors are presented in percentage form for allowing a comparison. Since the analyses are performed with simplified models of buses, a comparison is proper than the assessment of bare values of midpoint impact factors.

The hierarchical perspective is chosen in the evaluation as it is considered to be the most realistic and neutral approach.

\subsection{Comparison methodology of different powertrains}

We will compare different powertrains in terms of environmental impact, and we will explain below the methodology we adopted. There are many factors that may be used to define the performance of a bus in terms of environmental impact. Mid-point analysis provides actually a set of indices. A multi-criteria approach based on Pareto-optimality theory should be followed to compare two different powertrains (Mastinu et al. 2006). Applying Pareto theory to our case, a simple and rigorous way for a comparison is taking into account a single objective like GHG emission and compares the best CBG powertrain versus the best electric powertrain. In this case, two so called "Pareto-optimal solutions" are compared. Comparing optimal solutions is the only way that Pareto theory allows for a rigorous comparison (see Mastinu et al. 2006 for a rigorous comparison among different complex systems).

\subsection{Cradle-to-gate of CBG powertrain: midpoint analysis}

In the initial analysis of the products for the cradle-to-gate system boundaries, it is possible to identify the most relevant processes and parts for the finished product that is yet to be registered for on-road use. By inspection of Fig. 5 for the CBG powertrain, the motor, the CBG tanks, and the automatic gearbox have the most impact on the environment across all impact categories. This is coherent with the fact that these subsystems are very complex with a high number of components and overall have the highest mass (Fig. 6). 
Table 5 Different scenarios for the comparative LCA

\begin{tabular}{lll}
\hline Powertrain & Electric & CBG \\
\hline Fuel & Photovoltaic electricity (open ground) & Biomethane from manure \\
Emissions & Abrasive emissions & Combustion (Copert cycle \\
& & EEV) + abrasive emissions \\
Maintenance & 3 battery packs/lifecycle & Low maintenance (auxiliary battery) \\
\hline
\end{tabular}

\subsection{Cradle-to-gate of electric powertrain: midpoint analysis}

The results for the electric powertrain (Fig. 7) show how the battery pack system has the greatest influence among almost all midpoint categories, followed by the electric motor. The cooling system, the transmission, and the wiring system have a much smaller influence on the impact categories. This was expected since the battery accounts for $87 \%$ of the overall weight of the considered electric powertrain. In particular in the battery cell, the greatest impact is that of the copper and the lithium manganese oxide solution. On the electric motor, stator and rotor have the greatest impact on all indicators. Here, the silicon production and the copper production for the windings and connector have the most impact on all environmental factors.

It is important to point out that the choice of the electric motor greatly affects the results. Several LCA papers (see e.g. Auer and Meinke 2018) state that just changing the electric motor efficiency - without changing the motor type - can affect LCIA. This is even more evident when changing motor type, for example, from asynchronous motor to a permanent magnet motor. The problem is mainly related to the environment impact of permanent magnets. In the study, an asynchronous three-phase motor is chosen; however, permanent magnet motors are often used. This second case results in a greater impact on all categories due to the usage of rare earths (such

$\begin{array}{lll}\square \text { Engine cooling } & \square \text { Air intake } & \square \text { Automatic gearbox } \\ \square \text { Exhaust } & \square \text { ICE } & \square \text { Transmission }\end{array}$

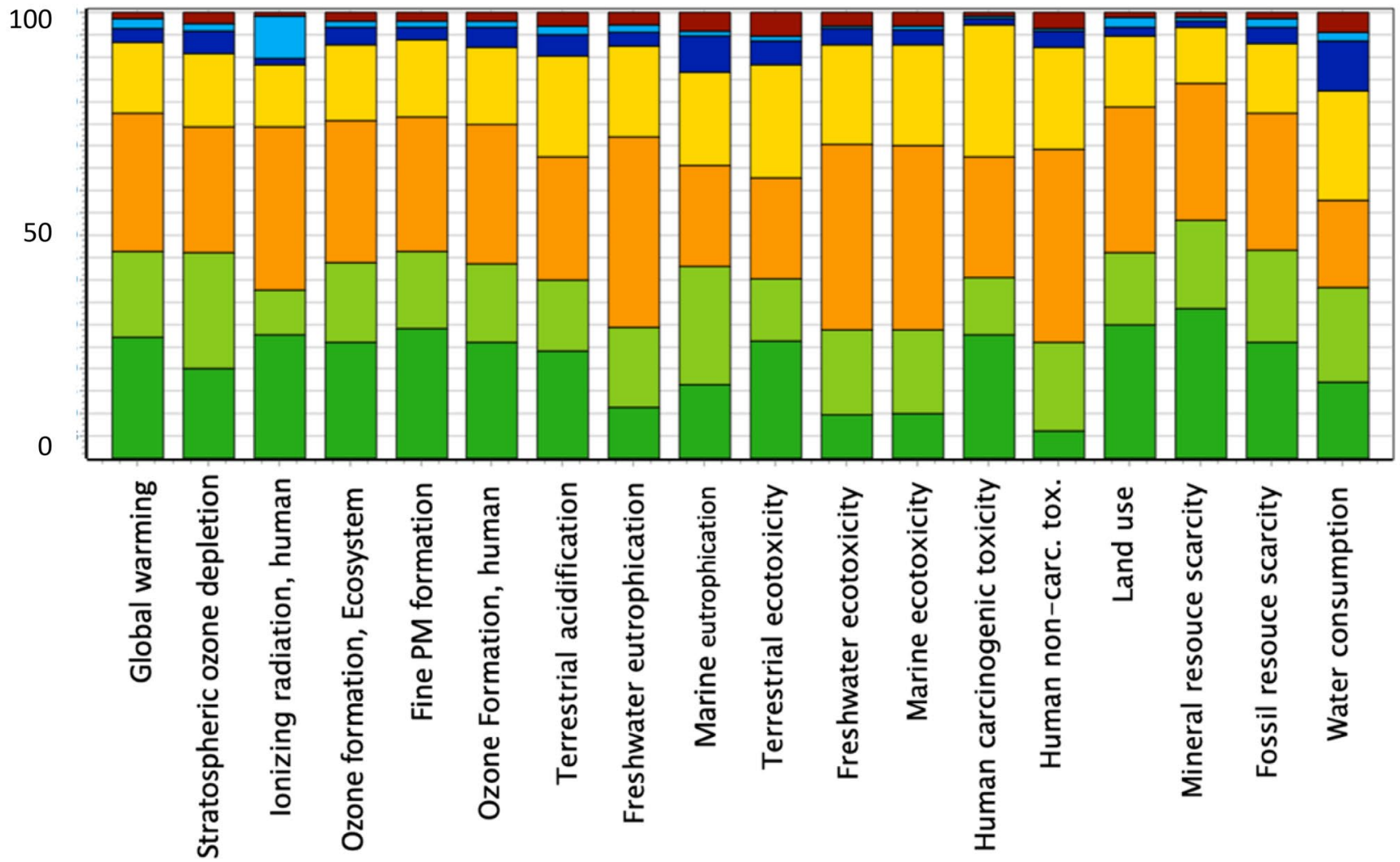

Fig. 6 Midpoint analysis CBG urban bus — cradle to gate. Percent values. See the "Data" section for accessing the originating values 


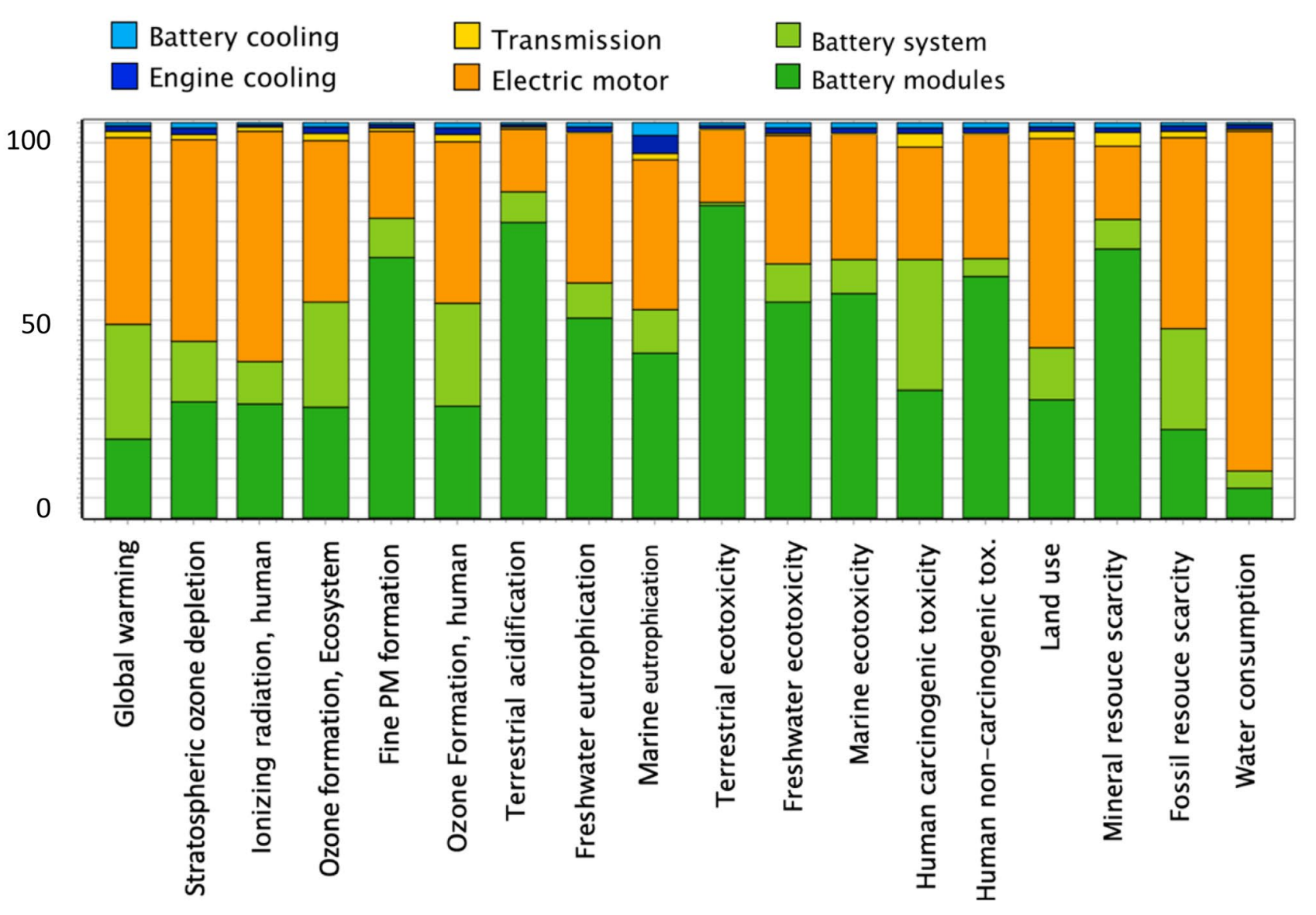

Fig. 7 Midpoint analysis electric urban bus — cradle to gate. Percent values. See the "Data" section for accessing the originating values

as neodymium) whose treatment processes are critical for the production of permanent magnets. We will go on considering the asynchronous motor since it is the most common design choice of manufacturers.

\subsection{Comparison of electric and CBG powertrains - cradle to gate: midpoint analysis}

When comparing the two powertrains, the electric powertrain turns out to have a greater impact in all scenarios but one (human carcinogenic potential, the sixth index from the right in Fig. 8). In particular, in terms of percentage, terrestrial acidification, terrestrial ecotoxicity, and water consumption, the CBG bus impact is only $10-15 \%$ of the electrical one.

Passing onto the endpoint evaluation of the damage on human health, the ecosystem, and resources, the results are consistent with the midpoint evaluation. The energy required to run in the urban transit is taken from UITP 2021.

\subsection{Cradle-to-grave of CBG powertrain: midpoint analysis}

In the midpoint characterization of the CBG powertrain (Fig. 9), fuel utilization and maintenance display how biomethane production generally has the highest impact on all indicators for the considered system. We consider the production of biomethane from manure. In particular, the methane purification nearly represents $100 \%$ of the emissions for global warming, stratospheric ozone depletion, ionizing radiation, terrestrial acidification, land use and water consumption. Overall the production of biomethane requires a relevant energy input and thus impacts negatively across all indicators. The main indicator that benefits from manure treatment is global warming. However, if normalization is applied to the midpoint impact, it can be seen that the global warming indicator has a much lower impact when compared to ecotoxicity or human health problems. The main indicator that benefits from manure treatment is global warming, with a negative value that is nearly $90 \%$ of the actual 


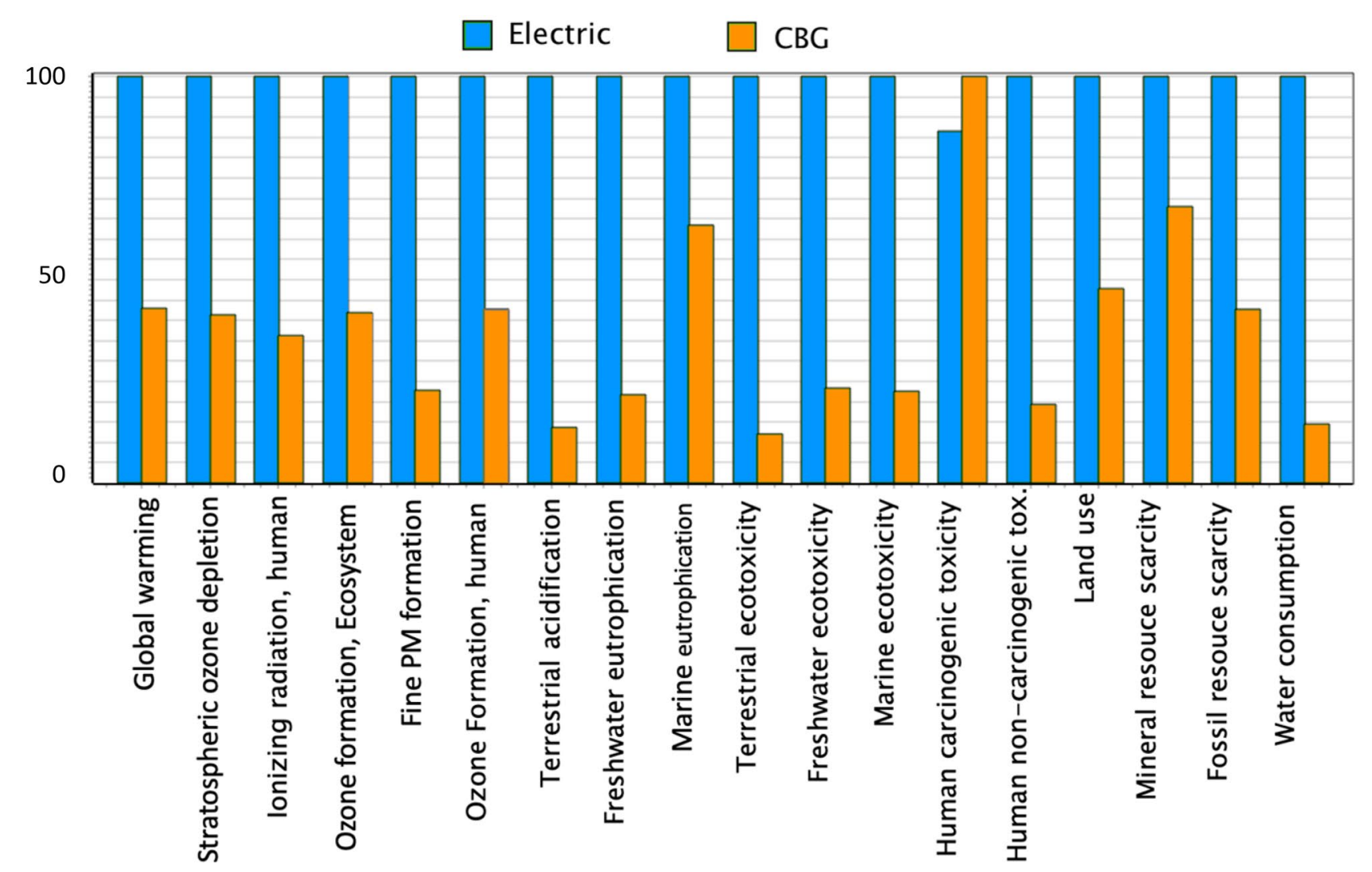

Fig. 8 Midpoint analysis comparison of CBG and electric powertrain — cradle to gate. Percent values. See the "Data" section for accessing the originating values

total emissions. However, if normalization is applied to the midpoint impact, it can be seen that the global warming indicator is very small when compared to ecotoxicity or human health problems. This result does not indicate that the avoided emissions are irrelevant, but rather that the global warming impact is less critical than other problems for this particular system.

\subsection{Cradle-to-grave of electric powertrain: midpoint analysis}

The characterization of the electric powertrain with the electricity consumption and maintenance shows that the battery pack and the electricity production have the most relevant impact on the product. From the results, the overall impact is shared in a 50-50\% proportion between the powertrain and the electricity production on all indicators (Fig. 10).

\subsection{Comparison of electric and CBG powertrains - cradle to grave: midpoint analysis}

When considering the whole life cycle of the two powertrains, the results are not as polarizing as in the previous cradle-to-gate approach. The results show that among all midpoint impact categories, the methane bus (blue) performs very badly on some critical sectors like particulate matter emissions or human non carcinogenic toxicity, but outperforms the electric vehicle (orange) on the global warming emissions or water and marine ecotoxicity and mineral resources. On some categories (stratospheric ozone depletion, ionizing radiation, fine pm formation, terrestrial acidification, human non-carcinogenic impact), the CBG powertrain is definitely more impactful when compared to the electric one. These categories are all related to emissions generated by the combustion or production of the methane. This is unmistakeable since in the cradle-to-gate analysis the CBG behaved in a better way compared to the electric one. The particulate emissions are particularly bad for the methane bus; here, the CBG has an order of magnitude of difference when comparing the $\mathrm{kg}$ PM2.5 eq values. This good performance of the biomethane driven bus is coherent with well-to-wheel (WTW) studies (CIB et al. 2016) that found that for a $100 \%$ renewable biomethane from manure, its impact is comparable to that of an electric vehicle that uses photovoltaic energy as in the figure below. The result is not comparable in values with the cradle-to-grave 


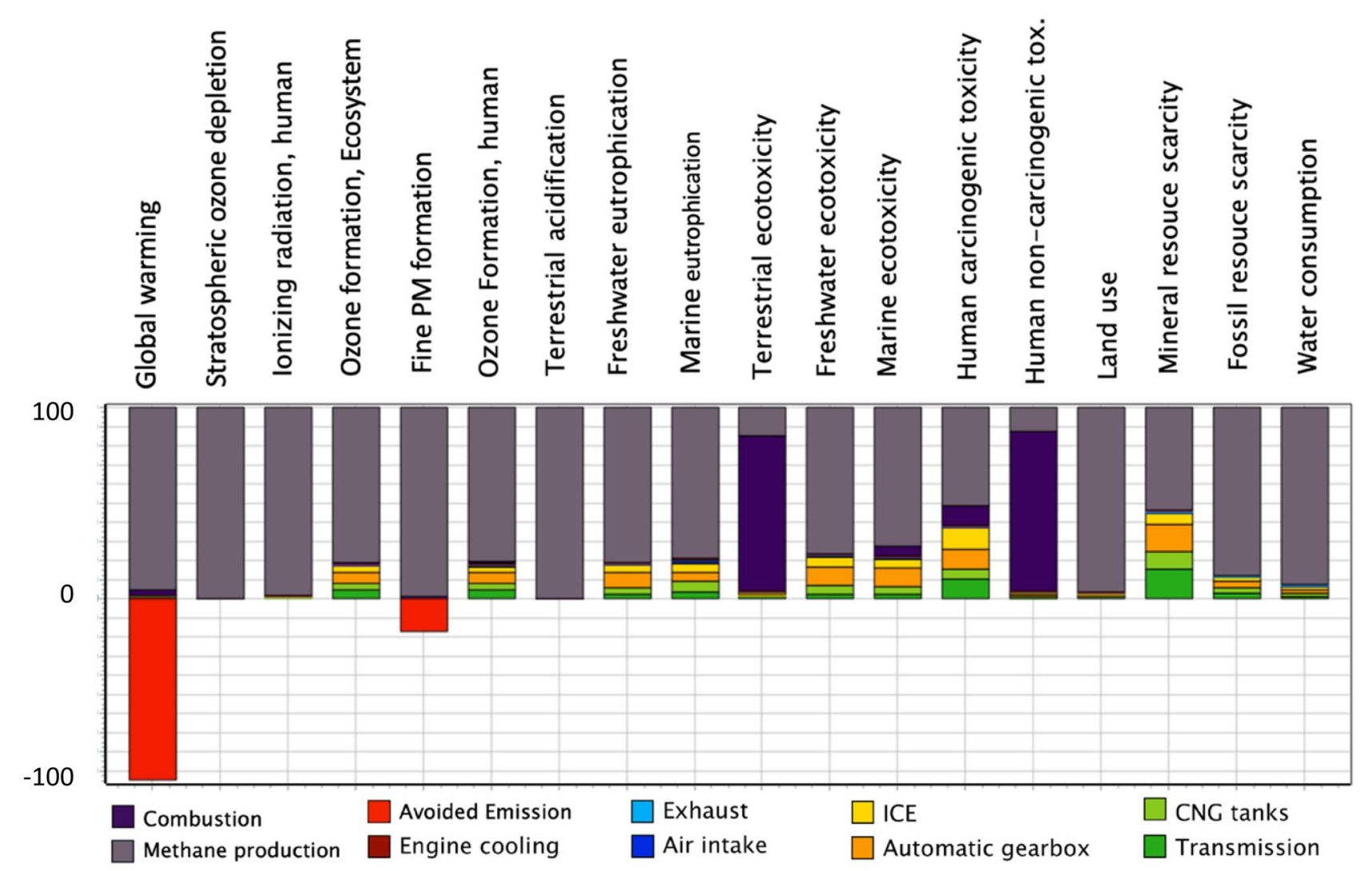

Fig. 9 Midpoint analysis CBG urban bus — cradle to grave. Percent values. See the "Data" section for accessing the originating values

comparison but supports the results in the global warming category, where the effect of biomethane production from manure is beneficial. The large gap in the GHG emission is related to the cradle-to-gate and maintenance of the electric vehicle (Fig. 11).

\subsection{Comparison of electric and CBG powertrains - cradle to grave: sensitivity analysis referring to maintenance}

Different levels of maintenance for the two vehicles during the life cycle are considered for a sensitivity analysis of the two products. The choice for the assessment on maintenance was made to evaluate a critical aspect of the life cycle in the case of public transport. The light maintenance of the CBG vehicle represents a common case, considering just a replacement of the on-board battery system for the auxiliary electronics. The heavy maintenance accounts the remote scenario where a change of all the CBG tanks is required. For the electric powertrain, maintenance levels are represented by the number of battery packs used in the life cycle of the powertrain. In the best case, no batteries were substituted. This scenario could represent an optimistic case where an improvement in the technology could allow no replacement on the battery pack. The actual scenario is the one where, in the most demanding scenario, the life of a battery pack is of about $5 / 6$ years, thus needing three sets of modules for its entire lifetime.

The low maintenance CBG has the best index for the global warming indicator even compared to the most optimistic case for the electric bus (one battery pack), while the other three electric scenarios are more than double. The actual scenario for the electric vehicle (three battery packs) has almost the worst impact. The change in maintenance of the CBG bus affects the most categories such as global warming, ozone formation, marine eutrophication, and fossil resources. The electric powertrain has a negative effect on indexes that are related to ecotoxicity, land use, freshwater eutrophication, and mineral resources. The land use is related to the occupation of soil by the photovoltaic on ground installation of the solar panels. The mineral resource scarcity is tied to the production of the batteries (Fig. 12). 


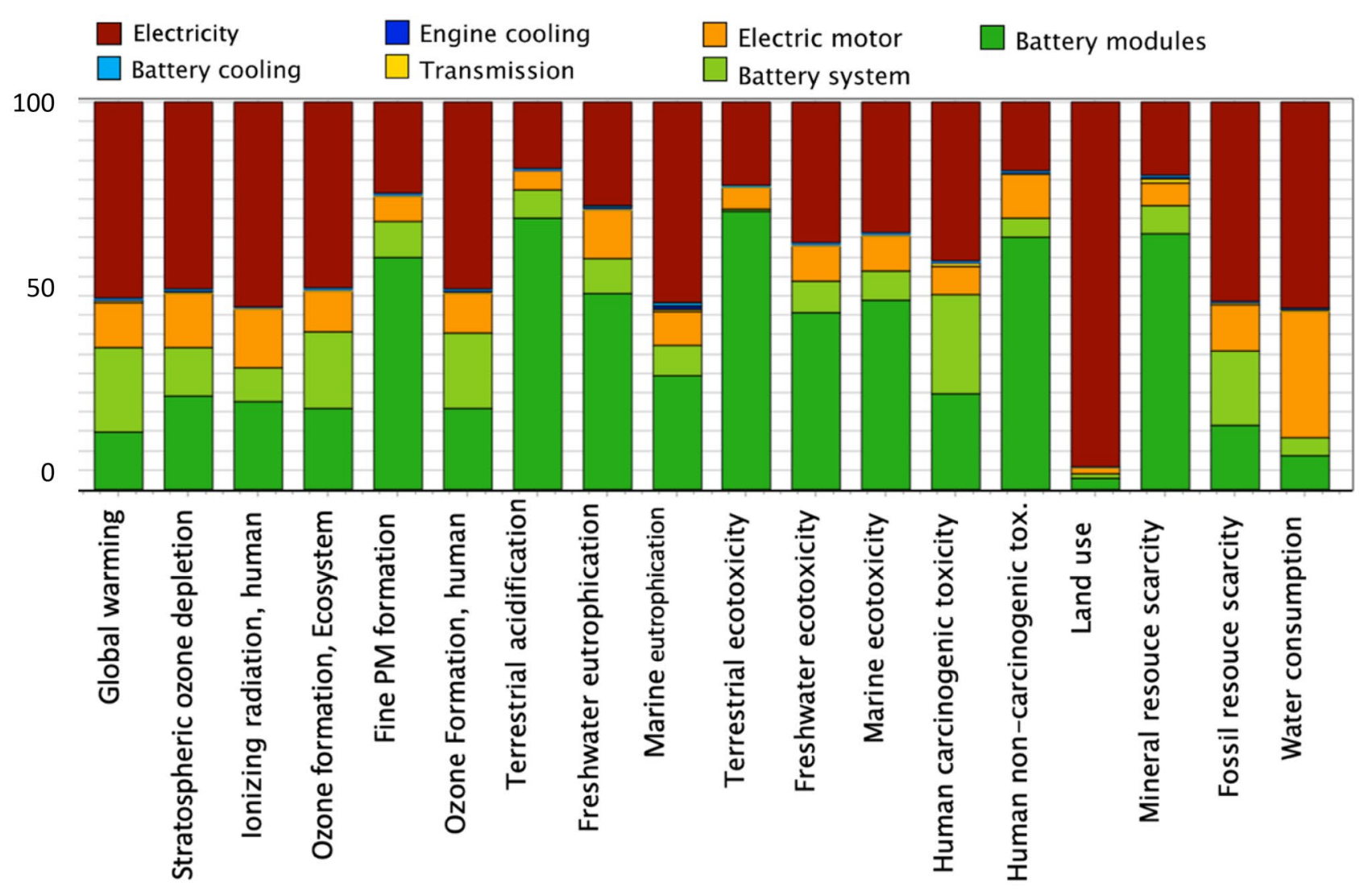

Fig. 10 Midpoint analysis of electric urban bus — cradle to grave. Percent values. See the "Data" section for accessing the originating values

\section{Discussion on interpretation of results}

In the presented midpoint assessment, the technology neutral approach was applied. For both of the two vehicles, the bestcase scenario compliant to today's technology was considered. Referring to GHG emissions, the aim was to compare the best electric powertrain versus the best CBG one. For the electric bus, no permanent magnets were considered, and for the CBG bus, the EURO VI emission standards were met. The electric energy supply was fully provided by renewable resources. We have resorted to Pareto theory to justify the comparison of the buses.

We aimed to reveal the most critical aspects in terms of environmental impact of the two technologies. Our contribution is to be intended as a preliminary evaluation and comparison of the two types of buses. For a more in-depth study, actual BOMs and real-life data must be gathered and considered. This document is still not sufficient to obtain any kind of environmental label. Nonetheless, although quantitatively approximated, our results may give sound qualitative information on environmental impact of the two buses. The soundness of the results is based on midpoint analysis that provides reliable information. The known drawback of midpoint analysis is that a synthesis is required, which may be not always an easy task. Except for the fine PM formation, the performance of CBG and electric bus are comparable, even if CBG bus seems better than the other one for global warming.

After the midpoint analysis, an endpoint analysis has been performed. The best CBG and the best electric powertrain are compared. Additionally, the worst CBG and worst electric bus are compared as well. The worst cases are constructed as follows. The worst CBG refers to biomethane production starting from a bad known electricity mix. The worst electric bus refers to electricity mix obtained from the mentioned bad electricity mix (University of Oxford 2019).

For what concerns human health and ecosystem, the electric urban bus has a better profile when compared to the biomethane one. This is not the case if resources are considered. Such results come from the SimaPro software computation and deserve a special critique. A generalization stating that electric buses are definitely better than CBM should be avoided. A number of reasons are as follows:

First reason. We neglected a number of factors ranging from the whole bus body analysis, to the environmental impact due to the production of components in different sites of the 


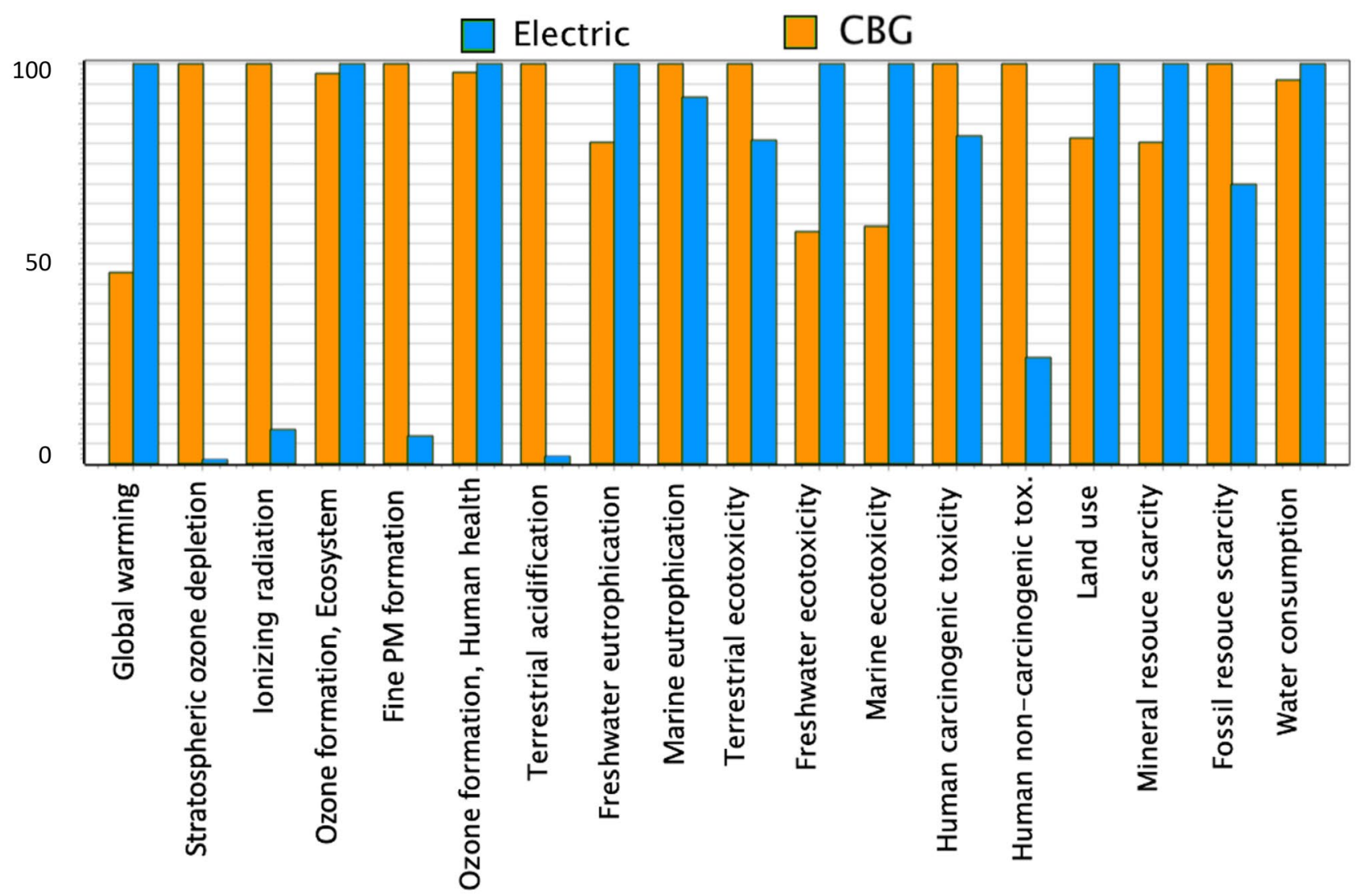

Fig. 11 Midpoint analysis comparison — cradle to grave. Percent values. See the "Data" section for accessing the originating values

world. Additionally, no infrastructure is considered, i.e., the environmental impact of the creation of fuelling or charging stations is not taken into account. The recycle of batteries and other parts of the buses is not considered as well.
Second reason. In our analysis, the crucial economic aspect of life cycle cost is not considered. Additionally, the social aspects that would impact the supply chain and thus the employment/ unemployment and welfare of the workers are not considered.

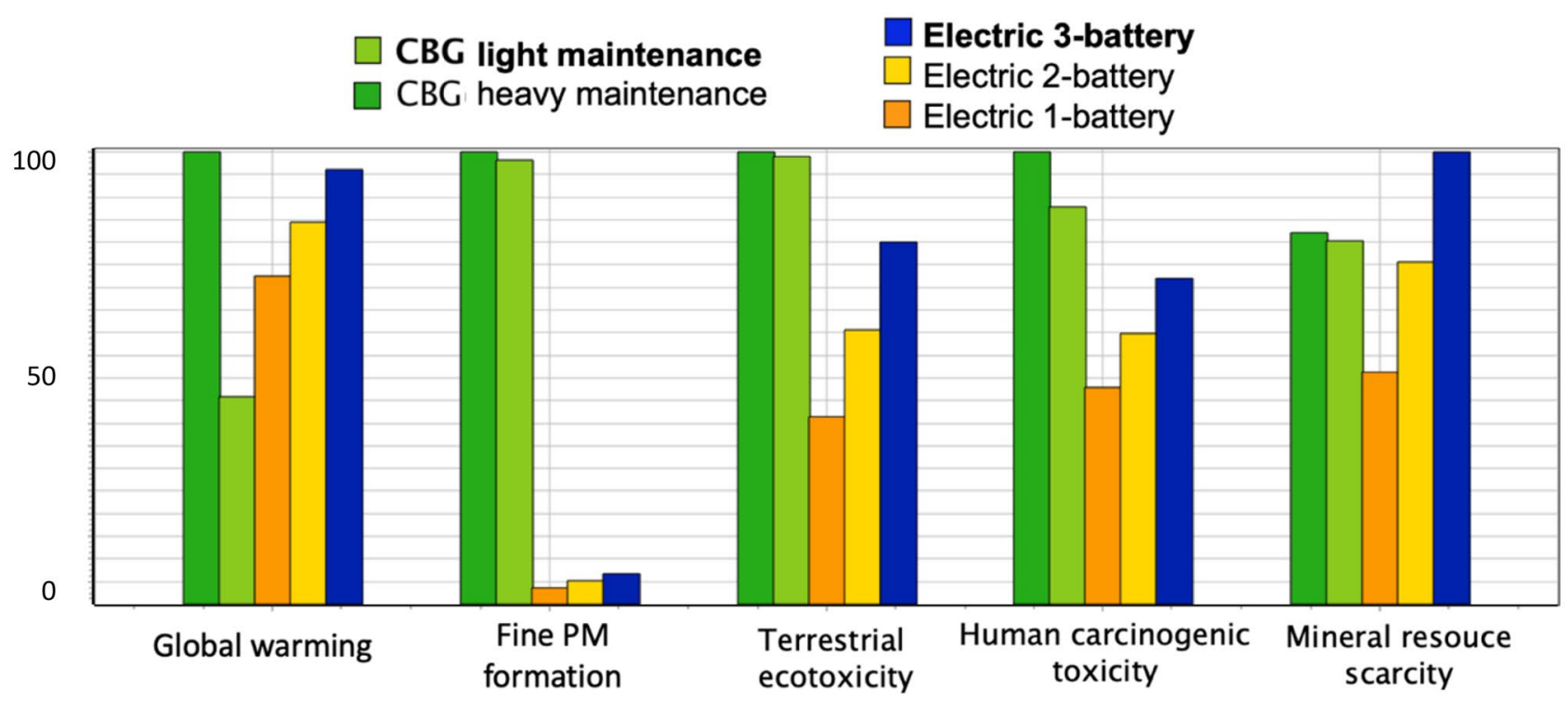

Fig. 12 Midpoint analysis comparison — cradle to grave. Percent values. See the "Data" section for accessing the originating values 
This could be analysed in a social life cycle assessment which is out of the scope of this paper. Geopolitical aspects concerning the access to resources are not considered.

Third reason. Sensitivity to weather conditions was not considered.

Fourth reason. A design change in any of the subsystems of the two buses would mean a substantial change of their endpoint environmental performance. For example, if permanent magnet motors would be used or the electricity mix would be changed, the endpoint performance of the electric bus would change considerably. The same would occur for the CBM if the electricity to produce biomethane would be from fossil fuels.

Fifth reason. The endpoint analysis refers to a synthesis that obviously has some bias coming from the data processing. We do not get into details here on how the SimaPro software computes the endpoint indices; we leave the interested reader the analysis.

Both the midpoint and endpoint analyses have been produced in terms of comparative assessment because the models used are relatively simple. In this case, a comparison seems proper than an evaluation based on bare values coming from computations.

In the Appendix, a well-to-wheel analysis is reported for a more complete overview of the comparison between the buses.

\section{Conclusion}

The aim of this paper was to provide preliminary but as complete as possible information on the environmental impact of two types of urban buses, namely, electric and biomethane fuelled. We focused on the bus powertrain only.

LCA has been adopted to compare the two technologies since it allows a more comprehensive study compared to the old well to wheel analysis.

The focus was mostly on midpoint analysis. The best CBG powertrain was compared to the best electric one.

Referring to cradle-to-gate performance, $\mathrm{CBG}$ powertrain outperforms the electric one.

Referring to cradle-to-grave performance, a more complex situation is to be considered, actually.

- methane production (biogas upgrading) is the most critical aspect for CBG.

- focus on batteries is fundamental for further abatement of emissions on all indicators for electric (notwithstanding the power mix that we considered here as full photovoltaic).
- electric powertrain (with full renewable power mix) has a good overall performance; $\mathrm{CBG}$ is competitive although locally slightly pollutant.

We also performed an endpoint analysis. In such an analysis, we considered both the best and the worst powertrains belonging to the two technologies. Despite the endpoint analysis is difficult to be interpreted and cannot be reliably considered, the electric powertrain performs better that the other referring to human health and ecosystem. The opposite occurs for resources.

Finally, we would conclude that when the technology for electric buses will be fully developed, they could be a good solution for the environment. If tailpipe emissions are not considered - but overall emissions are - CBG bus is better than the electric one for what concerns global warming.

The analysis performed in the paper suggests a further investigation. Both in the transient and in the future, a reasonable solution could be a hybrid electric-CBG bus. This solution may benefit from both of electric and CBG technology. Local emissions could be kept near to zero when the hybrid bus would run electric in downtown areas. The sensitivity to weather conditions and a reduced charging infrastructure could be attained. The very low global warming potential of CBG could be fully exploited.

\section{Appendix 1 Well to wheel comparison of photovoltaic electric bus versus anaerobic biomethane gas-fuelled bus}

\section{Midpoint analysis}

The LCA analysis has been compared to a well to wheel analysis. Overall, the CBG bus is more impactful than electric bus on all categories but two. The avoided methane emissions from manure are beneficial for global warming emission of the CBG bus. Additionally, land use is better for CBG bus because the photovoltaic electricity production is prone to open field occupation. By comparing the results in Fig. 13 with the cradle to grave in Fig. 11, we see that both vehicle production and maintenance affect various impact factors. Indicators for ecotoxicity, eutrophication, and ozone formation change drastically when the whole life cycle is evaluated. The same can be said for mineral resource scarcity and water consumption due to the production of the battery modules. 


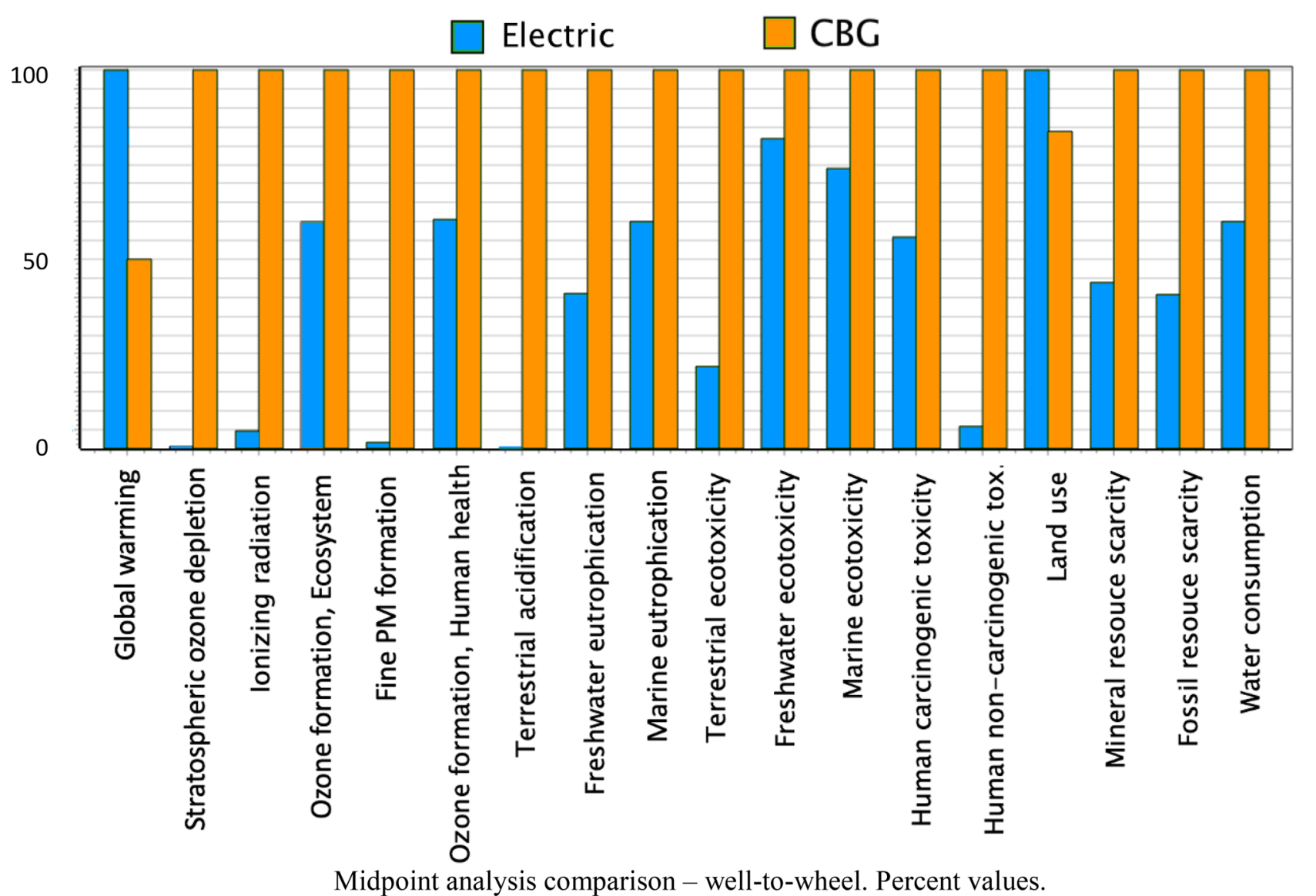

Fig. 13 Midpoint analysis comparison — well-to-wheel. Percent values

Supplementary Information The online version contains supplementary material available at https://doi.org/10.1007/s11367-021-02013-w.

Acknowledgements Dr. S Gaboardi, dr-ing P Trevisan from Lombardy Mobility Cluster are gratefully acknowledged for their support. A particular thank to dr-ing R Gaudio, expert of CBG buses who revised carefully the manuscript. Dr-ing G Smargiassi and dr R Giraldi from Invitalia are gratefully acknowledged for the support they gave for the production of this paper. This study was originally performed in support of the NeobusITA project of the Politecnico di Milano. The project was commissioned by Invitalia on behalf of the Italian Ministries of Economic Development (MISE) and Transportation (MIT). The study was supporting the "Piano Strategico Nazionale della Mobilità Sostenibile" (PSN-MS - National Strategic Plan of Sustainable Mobility). The Italian Ministry of Education, University and Research is acknowledged for the support provided through the Project "Department of Excellence LIS4.0 - Lightweight and Smart Structures for Industry 4.0."

Funding Mur "Department of Excellence LIS4.0 - Lightweight, and Smart Structures for Industry 4.0."

Data availability Data can be retrieved from the public repository of the Politecnico di Milano: www.re.public.polimi.it. Search for: Mastinu G, Solari L, Data used in the paper Electric and biomethane fuelled urban busses, Politecnico di Milano (2021).
Open Access This article is licensed under a Creative Commons Attribution 4.0 International License, which permits use, sharing, adaptation, distribution and reproduction in any medium or format, as long as you give appropriate credit to the original author(s) and the source, provide a link to the Creative Commons licence, and indicate if changes were made. The images or other third party material in this article are included in the article's Creative Commons licence, unless indicated otherwise in a credit line to the material. If material is not included in the article's Creative Commons licence and your intended use is not permitted by statutory regulation or exceeds the permitted use, you will need to obtain permission directly from the copyright holder. To view a copy of this licence, visit http://creativecommons.org/licenses/by/4.0/.

\section{References}

Agostini A (2006) JRC — avoided methane emissions from manure digestion. European Commission - Joint Research Centre, Institute for Energy and Transport, Cleaner Energy Unit

Argonne National Laboratory (2012) Material and energy flows in the materials production, assembly, and end-of.life stages of the automotive Lithium-Ion battery life cycle., U.S. Department of Energy

Auer J, Meinke A (2018) Comparative life cycle assessment of electric motors with different efficiency classes: a deep dive into the trade-offs between the life cycle stages in ecodesign contex. 
Int J Life Cycle Assess 23:1590-1608. https://doi.org/10.1007/ s11367-017-1378-8

Beltran A, Cox B, Mutel C, van Vuuren DP, Vivanco DF, Deetman S, Edelenbosch OY, Jeroen Guine J, Tukker A (2020) When the background matters using scenarios from integrated assessment models in prospective life cycle assessment. J of Cleaner Prod 259:120904. ISSN 0959-6526

Bouter A, Hache E, Ternel C, Beauchet S (2020) Comparative environmental life cycle assessment of several powertrain types for cars and buses in France for two driving cycles: "worldwide harmonized light vehicle test procedure" cycle and urban cycle. Int J Life Cycle Assess 25(8):1545-1565. https://doi.org/10.1007/ s11367-020-01756-2

Choi W, Song HH (2014) Well-to-wheel analysis on greenhouse gas emission and energy use with natural gas in Korea. Int J Life Cycle Assess 19(4):850-860

CIB, Anigas, NGV Italy, Legambiente, Confagricoltura (2016) Documento per la piattaforma biometano. (Italian Committee for Biomethane, NGV Italy, Legambiente, Confagricoltura - Document for the Biomethane Platform)

Ciuffo B, Raposo MA (2020) The future of road Transport - Implications of automated, connected, low carbon and shared mobility, EU Science Hub - Publications Office of the European Union, ISSN 1831-9424

CLM (Lombardy Mobility Cluster) (2021) private communication to the Authors, www.clusterlombardomobilita.it

Cox B, Castillo A, Mutel C (2017) Environmental assessment of current and future urban buses with different energy sources, EVS30 Symp. Stuttgart, Germany, October 9 - 11, 2017

Dai Q, Jarod CK, Gaines L, Wang M (2019) Life Cycle Analysis of Lithium-Ion Batteries for Automotive Applications

Duan H, Hu M, Zuo J, Zhu J, Mao R, Huang Q (2017) Assessing the carbon footprint of the transport sector in mega cities via streamlined life cycle assessment: a case study of Shenzhen, South China. Int J Life Cycle Assess 22(5):683-693

Duan N, Khoshnevisanb B, Lin C, Liu Z, Liu H (2020) Life cycle assessment of anaerobic digestion of pig manure coupled with different digestate treatment technologies

Emisia (2020) COPERT - The Industry Standards Emission Calculator. https://www.emisia.com/utilities/copert/. Accessed Jan 2021)

EPA - Environmental Protection Agency (USA) (2016) Regulations for Greenhouse Gas Emissions from Commercial Trucks \& Buses

Ercan T, Tatari O (2015) A hybrid life cycle assessment of public transportation buses with alternative fuel options. Int J Life Cycle Assess 20(9):1213-1231

European Commission (2019) Green New Deal Brussels

European Commission (2020) Sustainable and smart mobility strategy - putting European transport on track for the future, Brussels

Faber cylinders (2020) Cylinders for compressed natural gas (CBG). http://www.faber-italy.com/eng-product-CBG.asp

Fearghal R, Caulfield B (2010) Examining the benefits of using bioCBG in urban bus operations. Transp. Res. Part D: Transport and Environment, Vol. 15, Issue 6, p.362-365, ISSN 1361-9209.

Giuntoli J, Agostini A, Edwards R, Marelli L (2017) JRC — solid and gaseous bioenergy pathways: input values and GHG emissions

Gis W, Kruczyński S, Taubert I, Wierzejski A (2017) Studies of Energy Use by Electric Buses in SORT Tests. https://doi.org/10.19206/ CE-2017-323

Ghate AT, Qamar S (2020) Carbon footprint of urban public transport systems in Indian cities. Case Stud Trans Policy 8(1): ISSN 2213-624X

Grigoratos T, Fontaras G, Giechaskiel B, Martini G (2015) JRC assessment of the heavy-duty natural gas technology. Euro Commission - Joint Res Centre Inst Energy Transport

IEA (2020) Europe regional profile - electricity production. https:// www.iea.org/regions/europe. Accessed Jan 2021)
International Standard Organization (2006) ISO 14040:2006b. Environmental Management - life cycle assessment — principles and framework

Iveco Bus (2020a) Cityclass Iveco Brochure

Iveco Bus (2020b) Technical datasheet - Urbanway 12 m Bus Low Floor - Cursor 8 CBG EURO VI

Johnson TV (2010) Review of CO2 Emissions and Technologies in the Road Transportation Sector. SAE Int Jou of Engines 3(1):1079-1098

Joint Research Centre (2020) La banca dati dei fattori di emissione medi del trasporto stradale in Italia. http://www.sinanet.isprambiente.it/ it/sia-ispra/fetransp. (JRC ISPRA - Data for average the emissions of road transport in Italy). Accessed Jan 2021)

Kollamthodi $\mathrm{S}$ et al (2016) The role of natural gas and biomethane in the transport sector. Transp Enviro Ricardo Energy Environ

Mastinu G, Gobbi M, Miano C (2006) Optimal design of complex mechanical systems with application to vehicle engineering, Springer, Berlin, ISBN-10 : 364207071X, ISBN-13 : 978-3642070716

Mastinu G, Matta A, Trevisan P, Gaudio R, Solari L, Comolli F, Frigerio N, Nisoli F (2020) Analisi E Studi Sulla Filiera Del Trasporto Pubblico Locale - Progetto Neobusita (Analysis and Study of the National Industry of Local Public Transport - NEOBUSITA Project) - Final Report, Politecnico di Milano, Department of Mechanical Engineering

Mathe S (2014) Integrating participatory approaches into social life cycle assessment: the SLCA participatory approach. Int J Life Cycle Assess 19(8):1506-1514

Mercedes-Benz (2019) Citaro urban bus. https://www.mercedes-benzbus.com/it_IT/models/ecitaro.html. Accessed Jan 2021)

Mendoza BA et al (2018) When the background matters - using scenarios from integrated assessment models in prospective life cycle assessment. Jou of Ind Ecology 24(1):64

National Collaborating Centre for Environmental Health (2011) Air quality and community health impact of animal manure management. https://www.ncceh.ca/sites/default/files/Air_Quality_and_ Animal_Manure_Sept_2011.pdf. Accessed Dec 2020)

Nordelöfa A, Romareb M, Tivandera J (2019) Life cycle assessment of city buses powered by electricity, hydrogenated vegetable oil or diesel. Transp. Res. Part D: Transport and Env 75:211-222. ISSN 1361-9209

Papadimitriou Y, Mellios G (2020) ERTE 2020 - European Transport and Emissions Trends Report. Emisia

Poeschl M, Ward S, Owende P (2011) Environmental impacts of biogas deployment e Part I: life cycle inventory for evaluation of production process emissions to air. Jou of Cl Prod 24:168-183

Poeschl M, Ward S, Owende P (2012) Environmental impacts of biogas deployment Part II: life cycle assessment of multiple production and utilization pathways. Jou of Cl Prod 24:184-201

PRé Consultant (2020) SimaPro - LCA Software for fact based sustainability. https://simapro.com/. Version 9.0

PRé Sustainability (2016) LCIA: the ReCiPe model https://www.rivm. nl/en/life-cycle-assessment-lca/recipe. Accessed Dec 2020)

PRé, various authors (2020) SimaPro database Manual - Methods Library.

Price-Waterhouse-Coopers (PWC) (2016) Megatrends https://www.pwc. $\mathrm{com} / \mathrm{gx} / \mathrm{en} /$ government-public-services/assets/five-megatrendsimplications.pdf. Accessed Dec 2020)

Prussi M, Yugo M, Prada L, De Padella M, Edwards R (2020) JEC Well-To-Wheels report v5, EUR 30284 EN Publications Office of the European Union Luxembourg 978-92-76-20109-0 (online). https://doi.org/10.2760/100379. JRC121213

Rehl T, Lansche J, Müller J (2012) Life cycle assessment of energy generation from biogas - attributional vs. consequential approach. Ren Sust En Rev 16(6):3766-3775, ISSN 1364-032

Russell S (2019) Estimating and reporting the comparative emissions impacts of products. World Resources Institute 
Schwarz L, Stumper B, Bargende M, Dreyer S et al (2019) Environmental assessment of the end-of-life phase of alternative and conventional propulsion systems in the context of life cycle assessment. SAE TP. 2019-01-5013

Shanmugam K et al (2019) Social cost benefit analysis of operating compressed biomethane (CBG) transit buses in cities of developing nations: A case study. Sust 11(15) Article number 4190

Silvestri L, Forcina A, Arcese G, Bella G (2019) Environmental analysis based on life cycle assessment: an empirical investigation on the conventional and hybrid powertrain, SAE TP, 2019-24-0245, ISSN: 0148-7191

Spielmann M, Scholz RW, Tietje O, De Haan P (2005) Scenario modelling in prospective LCA of transport systems: application of formative scenario analysis. Int J Life Cycle Assess 10(5):325-335

STARK Automotive (2020) https://it.stark-automotive.com/

Timonen K, Sinkko T, Luostarinen S, Tampio E, Joensuu K (2019) LCA of anaerobic digestion: emission allocation for energy and digestate. J Clean Prod 235:1567-1579, ISSN 0959-6526

UITP (2019) https://www.uitp.org/publications/global-bus-survey/. Accessed June 2020)

UITP (2020) Bus fleet renewal checklist. https://www.uitp.org/ publications/bus-fleet-renewal-checklist/. Accessed Dec 2020)

UITP (2020) Clean Bus Europe Platform. https://www.uitp.org/news/ clean-bus-europe-platform-joins-forces-with-sustainable-bus-innew-content-collaboration/. Accessed Dec 2020)
UITP (2021) UITP SORT \& E-SORT brochures https://www.uitp.org/ publications/uitp-sort-e-sort-brochures/. Accessed Apr 2021)

UNFCCC (2016) United Nations Framework Convention on Climate Change - Paris Agreement

United Nations (2020) https://sdgs.un.org/goals. Accessed Jan 2022)

University of Oxford (2019) Our world in data - electricity mix. https:// ourworldindata.org/electricity-mix

Velandia Vargas JE, Falco DG, da Silva Walter AC, Cavaliero CKN, Seabra JEA (2019) Life cycle assessment of electric vehicles and buses in Brazil: effects of local manufacturing, mass reduction, and energy consumption evolution. Internatl J Life Cycle Assess 24(10):1878-1897

ZF (2019) Product overview - axle and transmission systems for buses \& coaches. https://www.zf.com/products/en/buses/downloads/ downloads.html. Accessed June 2020)

ZF (2020) Power electronics for electric drives. https://www.zf. com/products/en/buses/products_50817.html. Accessed June 2020)

Zhang L, Wang S, Qu X (2021) Optimal electric bus fleet scheduling considering battery degradation and non-linear charging profile. Transp Res E Logist Trans Rev 154. https://doi.org/10.1016/j.tre. 2021.102445

Publisher's Note Springer Nature remains neutral with regard to jurisdictional claims in published maps and institutional affiliations. 